\title{
El comercio en Sonora: una visión desde la perspectiva de su evolución
}

\author{
Carmen O. Bocanegra Gastelum*
}

\begin{abstract}
Resumen. El comercio es una de las actividades más antiguas en la historia del hombre. Si bien éste comenzó con el trueque de bienes para la supervivencia diaria, con el transcurso de los siglos ha alcanzado un alto grado de complejidad expresado, entre otras cosas, en el tipo y volumen de mercancías que se intercambian, así como en las características de los establecimientos en los cuales se lleva a cabo el proceso de oferta-demanda.

El presente artículo tiene como objetivo analizar las distintas etapas por las cuales ha transcurrido el comercio en Sonora, con particular énfasis en el último cuarto de siglo, periodo en el que la competencia comercial ha experimentado transformaciones profundas relacionadas con el tamaño, origen y conformación de los establecimientos, la inducción de formas de consumo, la distribución espacial y los vínculos entre lo global y lo local.

Palabras clave: Comercio, consumo, oferta-demanda.
\end{abstract}

\begin{abstract}
Commerce is one of the oldest activities in the history of man. Although this began with the exchange of goods for the daily survival, with the course of the centuries has reached a high degree of expressed complexity, among other things, in the type and establishments in which it takes supply-demand process.

The objective of the present article focus on the analysis of the different stages by which the commerce in Sonora has passed, with particular emphasis in the last quarter of century, period in which the commercial competition has experienced deep transformation related to the size, origin and conformation of the establishment, the induction of consumption forms, the space distribution and the bonds between local and global exchange.

Keywords: Commerce, consumption, supply-demand
\end{abstract}

* Profesora-investigadora del Departamento de Economía de la Universidad de Sonora. Correo electrónico: cboca@pitic.uson.mx 


\section{Introducción}

Una de las actividades económicas que históricamente se ha destacado en la frontera norte de México es la comercial. A través de las redes formadas por el comercio, las entidades norteñas se integraron a la economía del mercado interno, pero también tendieron vínculos con el mercado internacional. De hecho, el comercio es punta de lanza en la integración de los procesos económicos. En este sentido, el objetivo de este trabajo es analizar las características de la actividad comercial interna al detalle en el estado de Sonora, desde la década de los sesenta hasta la actualidad (2006), poniendo énfasis en los últimos 20 años. Las dos últimas décadas han sido testigo de un proceso de reestructuración comercial generada por elevados niveles de competitividad, mismos que se han acentuado a partir de la década de los noventa del siglo pasado, como resultado del desplazamiento de empresas comerciales ubicadas más allá de la frontera tradicional de Arizona y California, hacia el interior del mercado sonorense.

Particularmente se destaca la concentración, distribución, localización y tipo de agente comercial presente en cada una de las etapas por las que ha transcurrido la actividad comercial de bienes de consumo personal al detalle en el estado de Sonora.

Para lograr el objetivo ya mencionado se parte de dos marcos: uno teórico y otro histórico. En el caso del primero nos apoyamos en algunos planteamientos de autores clásicos de la economía como Alfred Marshall, Carlos Marx y Adam Smith. Los tres destacan la relevancia del comercio interno como parte del funcionamiento de las economías de mercado y su dinámica a través de la competencia; y para cubrir el expediente del segundo, el histórico, se realiza un análisis retrospectivo acerca de los distintos periodos por los que ha transcurrido el comercio en Sonora, mismo que nos permitirá tener mejores elementos de juicio para comprender la etapa actual.

\section{Elementos teóricos y de contexto}

Sobre la importancia del intercambio de productos dentro de la estructura económica, Alfred Marshall (1954) señala en su libro Princi- 
pios de economía que "el carácter del hombre ha sido moldeado por su trabajo cotidiano y por los recursos materiales que con él se procura mucho más que por cualquier otra influencia".

Del mismo modo, en su obra El capital Carlos Marx argumenta sobre la relevancia del capital comercial en las economías de mercado:

El capitalista comercial se halla encuadrado en la órbita de la circulación y su función consiste exclusivamente en servir de vehículo al cambio de mercancías [...] para que este capitalista exista, basta con que se den las condiciones necesarias para la circulación simple de mercancías y de dinero. Esta constituye su condición de existencia; el comercio imprime, por tanto, a la producción un carácter orientado cada vez más hacia el valor de cambio. La metamorfosis de las mercancías consiste: 1) en el cambio de distintas mercancías entre sí; 2) en la transformación del dinero en mercancías-compra. A estas funciones se reduce la función del capital comercial [...] Su forma es siempre $\mathbf{D}$ - $\mathbf{M}$ - $\mathbf{D}^{\prime}$ movimiento característico del capital comercial.

Sobre la importancia de la actividad comercial, Adam Smith consideró que ésta era imprescindible para la evolución de las economías, por lo tanto, destacó el comercio como parte del proceso económico, representando una fase del mismo, por lo que la reactivación de esta actividad podía contribuir al desarrollo de dicho proceso. Pero no sólo era importante para la vida económica de las sociedades, sino que consideraba la habilidad de intercambiar una cosa por otra como parte de la naturaleza del ser humano:

Tan pronto como se hubo establecido la división del trabajo, sólo una pequeña parte de las necesidades de cada hombre se pudo satisfacer con el producto de su propia labor. El hombre subviene a la mayor parte de sus necesidades cambiando el remanente del producto de su esfuerzo, en exceso de lo que consume, por otras porciones del producto ajeno que él necesita. El hombre vive así, gracias al cambio, convirtiéndose, en cierto modo, en mercader, y la sociedad misma prospera hasta ser lo que realmente es, una sociedad comercial. 
La cita anterior expresa claramente la relevancia que ejerce el comercio, entendido como la transacción para la adquisición de un bien para el consumo personal, ya sea como artículo de primera necesidad o de lujo. Su importancia reside en que incluye el ámbito económico, lo que permite percibir el grado de avance en la organización de la sociedad y el nivel en que ésta puede satisfacer sus propias necesidades. Esto es, medir el grado de crecimiento que puede alcanzar y, por supuesto, el de su desarrollo. Es importante destacar esto dada la poca relevancia que se le ha dado a esta actividad en la historia económica de Sonora y lo mucho que se tiene que decir sobre la misma.

A través de la historia comercial sonorense de principios del siglo XIX y hasta la actualidad, podemos distinguir cuatro etapas. Cada momento en la historia comercial se distingue por diferentes agentes comerciales, origen de los mismos y formas de hacer competencia. En este apartado se resumen para ampliarlas en el siguiente. ${ }^{1}$

Un primer periodo remite al intercambio comercial que existía a principios del siglo XIX entre los comerciantes radicados en el estado con similares europeos de Inglaterra, Francia y Alemania. En esta época, los primeros obtenían los artículos a través de créditos otorgados por los segundos, comerciantes que dejaron gran influencia en el consumidor local.

La segunda etapa corresponde a finales del siglo XIX y primera mitad del xx. Este capítulo se caracterizó por la entrada de productos básicos y de lujo provenientes de los estados de Arizona y California a territorio sonorense. Cabe destacar que la adquisición de la mercancías se efectuaba al contado y que los agentes líderes del comercio eran los chinos.

Un tercer momento se ubica desde la década de los años cuarenta del siglo pasado hasta finales de los setenta. Este periodo se caracteri-

\footnotetext{
${ }^{1}$ Las etapas del comercio se refieren de manera general al comercio minorista o al detalle. Para ello, se utilizó la definición de Castillo Berthier (1994): “Menudeo o detalle es la actividad en la que un comerciante le vende directamente al último consumidor". Asimismo, se tomó la definición del INEGI: “...se entiende al detallista como el comerciante que vende al por menor. El comercio al por menor, como la compra de mercancías en grandes cantidades -al por mayor- para su reventa en pequeñas cantidades a los consumidores finales de manera directa" (XII Censo Comercial, 2000).
} 
zó porque el crecimiento del comercio se dio en estrecha vinculación con los sectores agrícola e industrial, nexos que en los sesenta dieron forma a los "combinados industriales". ${ }^{2}$ Esto permitió que el abastecimiento del mercado interno sonorense se ofreciera principalmente por productos elaborados en el estado y en el interior del país. Es importante mencionar que esto obedeció en gran medida a las políticas adoptadas por el gobierno federal, en lo referente a impulsar la industrialización a través de la sustitución de importaciones, lo que en esa época mejoró la vinculación entre el sector primario y el secundario. Empero, aun en estas condiciones el consumidor sonorense de ingresos medios y altos manifestaba preferencia por el producto de consumo personal estadounidense, mismo que en ocasiones podía adquirir de este lado de la frontera, en Nogales, Sonora, pero sobre todo en "el otro lado", Nogales y Tucson, Arizona.

El cuarto y último periodo se empieza a manifestar desde la década de los ochenta y continúa con más ímpetu en la actualidad. A partir de entonces, la frontera comercial trasciende definitivamente la línea divisoria entre los países y se ubica "virtualmente" en la capital del estado a través de la inversión extranjera directa. Este movimiento tiene la finalidad de comercializar toda clase de productos de procedencia extranjera, ya sean básicos o de lujo, con gran presencia de formas de consumo al estilo de vida americano. Las inversiones extranjeras directas son básicamente de Estados Unidos y en menor medida de Francia. Entre las empresas nacionales destacan establecimientos provenientes de los estados de Sinaloa, Coahuila y Nuevo León. En este cuarto episodio, en el cual se centra la atención del presente trabajo, observamos una gran competitividad impuesta por el capital comercial extranjero, que extrapola sus márgenes de acción hasta ubicarlos dentro del territorio sonorense. ${ }^{3}$

${ }^{2}$ Forma de organización económica adoptada durante el gobierno de Luis Encinas (1961-1967) para impulsar la industrialización a partir de las materias primas producidas por las actividades primarias. Para más detalles, véase Sonora. Desarrollo industrial, 1961-1967, Gobierno del Estado de Sonora-Dirección de Planeación y Fomento Industrial, Hermosillo, Sonora, 1967.

${ }^{3}$ Se toma la definición de competitividad de Jeannot Rossi (1999) por considerar que expresa claramente la disputa por los mercados, misma que se refleja en cada una de los momentos de la evolución del comercio minorista en Sonora: "La 
Esto provoca en el estado un gran desplazamiento de micros, pequeños y medianos comerciantes especializados, tanto locales como regionales. Al respecto, Marshall (1978) expresa en sus Obras escogidas: "Un vendedor al menudeo en cuanto logra atraerse una buena clientela disfruta de un monopolio local, limitado y parcial. Si hace mal uso de él acaba por perderlo tarde o temprano". Esta acción se puede observar en los comerciantes oriundos de la región, que al perder márgenes de competencia, después de haber monopolizado el mercado de la región, acaban por perderlo. Es el caso, por ejemplo, del grupo Valenzuela Hermanos, que a pesar de todos sus intentos cada vez es más desplazado del liderazgo comercial interno; así como el de la empresa departamental del grupo Mazón Hermanos, que terminó por ser vendida a Liverpool.

En los comercios pequeños la situación es peor aún, ya que éstos definitivamente abandonan el mercado por incosteable, dado que operan por su nivel de transacciones en reducida escala a precios muy altos. Marshall (1954) diría, refiriéndose a este tipo de competencia, que "las formas modernas de la vida industrial dan una mayor ocasión para la competencia". Podemos decir que la modernización ha traído altos márgenes de competencia entre los comerciantes ubicados en el estado, pero esto no refleja fielmente el grado de modernización de la sociedad sonorense, sino más bien el de países altamente industrializados. Sobre este aspecto, continua Marshall, "el significado estricto de la competencia parece ser la lucha de una persona contra otra respecto a la operación de compra o venta de cualquier bien. Esta clase de supervivencia es más intensa hoy que en la antigüedad". Considera también que la era moderna ha proporcionado nuevas oportunidades por la falta de honradez en el comercio, es decir, el progreso de la ciencia ha descubierto nuevos remedios para lograr que las cosas aparezcan en una forma distinta de lo que en realidad son, y ha hecho posibles muchas nuevas formas de adulteración. Con esto po-

competitividad, de manera simple y generalmente aceptada, consiste en lograr posiciones de dominio en los mercados respectivos en función de los precios y las calidades de los productos". 
demos entender la diversificación que se puede hacer de un mismo producto al atribuirle una serie de cualidades que realmente no posee $\mathrm{y}$, al mismo tiempo, ofrecerlo con una imagen muy llamativa y a un precio bajo. Es decir, un factor insustituible de apoyo a la moderna competencia comercial es la publicidad. Sobre lo mismo, Marshall sostiene que

...los comerciantes o productores que se hallan frente a un competidor que ofrece mercancías a un precio inferior del que puede ofrecerle un buen beneficio, se resienten de esta intromisión y se quejan de haber sido perjudicados, aun cuando pudiera ser cierto que los compradores de las mercancías más baratas estuviesen mucho más necesitados que ellos, con lo que la energía y sagacidad de su rival viene así a constituir una ganancia.

Continuando con Marshall (1978), sobre los beneficios que obtiene el comerciante señala:

Todo mercader tiene dificultades que vencer, riesgos que asumir y gastos que pagar, y no considera que todo ello vale la pena a menos que las diferencias en el valor de las mercancías que compra y vende en lugares distintos, le proporcionen un margen que le compense de su esfuerzo para salvar todos los obstáculos.

En este marco podemos ubicar a los comerciantes extranjeros, cuyos riesgos y gastos son, obviamente, mucho menores que en su país de origen. Siempre se parte de la premisa de que van a obtener más que buenas ganancias, gracias a sus altos niveles de competencia y bajos costos de operación. Asimismo, provocan en los comerciantes locales, principalmente en los micros, pequeños y medianos, altos riesgos por vencer y grandes pagos que no podrán realizar tan fácilmente, lo que los conducirá a una pérdida de su espacio comercial o a la desaparición definitiva. 


\title{
Cuatro episodios en la historia comercial de Sonora
}

\author{
Mercaderes europeos en Sonora \\ (Principios del siglo XIX a mediados del mismo)
}

A principios del siglo XIX, antes de que se vinculara el comercio sonorense con el de Estados Unidos, esta actividad se realizaba fundamentalmente a través de la relación que existía entre comerciantes sonorenses y europeos. El puerto de Guaymas, considerado "la puerta del mundo", sirvió como el principal contacto del estado con el exterior. El grupo de comerciantes locales estaba integrado, entre otros personajes, por los Camou, Escobosa, Möller, Robinson, Bulle, Hoffer, Ruiz, Aguilar e Iberri. ${ }^{4}$

Los comerciantes radicados en Sonora -dado que en su mayoría eran extranjeros- recibían mercancía de los proveedores europeos a crédito. El pago de las transacciones comerciales se efectuaba poco a poco, conforme se iba vendiendo la mercancía. En realidad, el comerciante que distribuía en el estado era intermediario del europeo. Algunos de los productos que entonces se distribuían eran telas, vinos, brandy, material de construcción y productos manufacturados. Las embarcaciones de los proveedores europeos también recorrían en el Golfo de California, La Paz, Mulege, San José y Mazatlán.

En el intercambio entre comerciantes locales y europeos el dinero en efectivo era realmente escaso, pues la base principal de estas transacciones era el crédito:

Hasta la propia aduana extendía crédito a los vendedores locales y del exterior, para que efectuaran el pago de sus aranceles. En algunos casos, a los comerciantes mexicanos se les daba hasta un año para pagar sus impuestos, mientras que a los extranjeros se les permitía efectuar sus pagos en 8 meses (Tinker, 1994).

\footnotetext{
${ }^{4}$ Camou, de origen francés radicado en Sonora. Los Hoeffer y Möller proceden de Alemania, el primero llego de St. Louis Missouri, Estados Unidos. En la entidad, el Sr. Möller funda la primera gran cervecería de Sonora. Para más detalles véase María B. Martínez de Castro (1995), Hermosillo de mis recuerdos, Casa de la Cultura de Sonora-Instituto de Cultura Superior de Sonora, Hermosillo, Sonora.
} 
Los comerciantes locales ofrecían en garantía, mientras se realizaba la venta de sus mercancías, minerales, madera y plata. Los artículos eran esperados en el puerto de Guaymas, de donde salían nuevamente para revenderse al interior del estado en la misma forma en que habían sido adquiridos, esto es, a crédito. El grupo de comerciantes tenía controlado el comercio en la región, ya que después de Baja California se deslizaron hacia Arizona y Chihuahua:

Los comerciantes de Guaymas y Hermosillo parecían constituir una fuerte y poderosa clase social, pero su posición económica era en realidad extremadamente débil. Sus transacciones comerciales seguían dependiendo del éxito de las principales actividades económicas del estado: la minería y la agricultura, básicamente la producción de trigo (Tinker, 1994).

A partir de la segunda mitad del siglo XIX, se reduce la influencia comercial de países europeos como España, Alemania y Francia, por el auge en el intercambio de productos provenientes de Estados Unidos. Primero por San Francisco, California, por vía marítima hacia el Puerto de Guaymas, y posteriormente por Arizona, con la llegada del ferrocarril hacia 1880 en Yuma. El uso del ferrocarril dinamizó aún más estas relaciones, permitiendo a los americanos ofrecer los productos básicos y de lujo a precios más bajos.

\section{Los chinos en Sonora}

(Segunda mitad del siglo XIX a los años treinta del siglo XX)

Es prácticamente imposible tratar de hacer una semblanza del comercio sonorense y no detenerse en el papel que desempeñaron los chinos en el comercio. Su importancia radica en el monopolio que ejercieron en esta actividad desde su llegada a Sonora hasta finales de la década de 1870. Desde entonces, se colocaron en esta entidad como la pequeña burguesía comercial que controló el comercio local a través de la venta de mercancías en general, tanto al menudeo como al mayoreo. Los chinos muy pronto ocuparon la posición que tenían las compañías europeas, alemanas, españolas y francesas. 
Aproximadamente en 1880, con la construcción de las vías del ferrocarril del tramo Guaymas-Hermosillo-Nogales, arribaron los primeros chinos a Sonora para ocuparse en dicho proyecto. No tardaron mucho en la construcción dado que eran grandes ahorradores, lo que les permitió hacer sus propios negocios a partir de las tiendas de abarrotes. A medida que progresaron en sus negocios personales, enviaron dinero a su país para que vinieran más chinos a Sonora a trabajar para ellos mismos. En un principio sólo llegaban al estado los hombres por dos razones: la primera era que Estados Unidos, temeroso de la proliferación de los chinos en su país, no permitía el paso a mujeres y niños, y la segunda consistía en que la introducción ilegal tanto a ese país como a México significaba graves riesgos para los familiares de los chinos, a los cuales éstos no querían someterlos. Los chinos que en esos momentos arribaban al estado eran en su mayoría campesinos y artesanos. ${ }^{5}$

Este grupo oriental construyó un verdadero imperio comercial, ${ }^{6}$ con cerca de dos mil pequeños locales de distribución en productos como alimentos, ropa, telas, sedas, porcelanas, abanicos, marfiles, kimonos, mantelería, vajilla, y muchos otros, con los cuales se dejó sentir su influencia aun cuando ésta no fue tan sustanciosa como la europea dado que, al mismo tiempo, los comerciantes chinos traían también mercancía americana en grandes cantidades. En la entidad formaron su colonia y crearon sus propias Cámaras de Comercio. Las dos tiendas comerciales más importantes vendían ropa y calzado y fueron la Tung Chung Lung y la Siu Fo Chong, localizadas en Cananea, Sonora, por la importancia que representaba la actividad minera en los ingresos de la economía del estado.

Durante este periodo se registró un aumento de la población china en el estado de Sonora. En 1900 se registraban 850 chinos, treinta años después, en 1930, había aproximadamente 3 571. Éstos impedían la ocupación de trabajadores locales, tanto de mujeres como de hombres, ya que hacían sentir su presencia hasta en las actividades más

\footnotetext{
${ }^{5}$ Primera Plana, 4 de septiembre de 1998.

${ }^{6}$ Como lo califica Martínez de Castro (1995) en su libro Hermosillo de mis recuerdos, p. 86.
} 
cotidianas practicadas por las mujeres como el lavado y planchado de ropa.

Pocos años después de la llegada de los chinos y su penetración en el comercio de la entidad, se presenta el intercambio de productos con Arizona. Esto permitió la adaptación del mercado interno a la compra-venta de bienes americanos de toda clase. "En todo el estado la adquisición de productos de consumo americano ya sobrepasaba la de productos europeos, mientras que hace diez años, los artículos de algodón y lana adquiridos en el estado eran exclusivamente europeos" (Tinker, 1994). La gran afluencia de estos productos provocó el desplazamiento o la desaparición de comerciantes sonorenses, los cuales para seguir permaneciendo en el mercado tuvieron que adaptarse a las reglas que imponía este nuevo comercio. La primera de ellas fue el pago al contado por los productos adquiridos para su venta al interior del estado. Obviamente, esto llevó a muchos comerciantes medianos y pequeños al cierre de su actividad. Otros tuvieron mejor suerte por la magnitud de su capital, pues se trasladaron a San Francisco, California, para proveerse de bienes de lujo y básicos que ofrecían al consumidor sonorense.

La élite de viejos comerciantes que pudieron adaptarse con mayor facilidad a las imposiciones del comercio con Estados Unidos fueron los Camou, Aguilar y Ortiz; mientras que entre los nuevos personajes se encontraban Manuel Mascareñas y Luis Martínez. La presencia de los productos de Estados Unidos a precios menores desplazó poco a poco a los europeos y al sistema de crédito con el cual se venían realizando las transacciones comerciales años atrás.

Esta vinculación comercial a través de las fronteras de Sonora, Arizona y California marcó el inicio de una etapa donde la influencia del producto estadounidense se convirtió en una costumbre del consumidor sonorense, al formarse la idea de que estos artículos eran más agradables a la vista, perdurables y de mayor calidad.

En 1919 empezó el hostigamiento para la expulsión de los chinos de Sonora por parte de comerciantes locales con el argumento que dominaban todo el comercio, principalmente el de las zonas mineras, hecho que culminó a mediados de los años treinta cuando el gobierno de Rodolfo Elías Calles emprendió su persecución y expulsión del esta- 
do, culminando una etapa del comercio para dar paso a otra donde la actividad estuvo más identificada con agentes del comercio regional. ${ }^{7}$

\section{Expansión agrícola y comercial}

(Principios de la década de los cuarenta y finales de los setenta)

El abasto de mercancías durante este periodo se presenta bajo tres modalidades: la primera de ellas proveía de mercancías extranjeras a los municipios ubicados en las zonas y perímetros libres; la segunda se sustentó en el pequeño comercio que se dedicaba a la venta de mercancía proveniente de otros estados de la república; y la tercera corresponde a mercancías importadas por empresarios de la región que se asociaron como comisionistas a empresas trasnacionales como la Massey Ferguson y la John Deer, que vendían implementos agrícolas para la actividad económica de punta en ese momento, la agricultura.

Ya para la década de los sesenta, el comercio ofrece bienes de consumo perecedero y no perecedero producidos en el país, mismos que van desplazando a los elaborados en la localidad. Esto se lleva a cabo mediante el surgimiento de la nueva clase empresarial de la época: los Gutiérrez, Robinson, Bours, Zaragoza, Mazón y los Hermanos Valenzuela, mismos que estaban ubicados en los principales municipios de la entidad (cuadros 1 y 2), es decir, donde se encontraban las actividades productivas más importantes y el comercio. En estos municipios y sus cabeceras se centralizaba la operatividad económica de las actividades. Cajeme, Navojoa y Hermosillo eran los ayuntamientos más representativos de la agricultura y la ganadería, además de la industria ligada a ellas.

Guaymas estaba dedicado primordialmente a la pesca de exportación; Nogales, frontera inmediata con Estados Unidos, era y continúa siendo una de las principales aduanas, además de haber sido a finales de los sesenta el primer municipio receptor de la industria maquiladora con destino al mercado de exportación. Estas cinco localidades salvaguardaban $56 \%$ de los comercios establecidos en la entidad. En los

\footnotetext{
${ }^{7}$ Para más detalles sobre el periodo de la comunidad china véase José A. Espinoza (1932), El ejemplo de Sonora, México.
} 


\section{Cuadro 1.}

Establecimientos comerciales en 1955 y población ocupada en el comercio en Sonora, 1950

(porcentaje de participación)

\begin{tabular}{lrrcr}
\hline & $\begin{array}{c}\text { Población } \\
\text { ocupada }\end{array}$ & $\%$ & $\begin{array}{c}\text { Establecimientos } \\
\text { comerciales }\end{array}$ & $\%$ \\
\hline Sonora & 163421 & 100.0 & 3502 & 100.0 \\
Comercio & 13874 & 8.4 & 352 & - \\
Hermosillo & 2549 & 18.3 & 704 & 10.5 \\
Cajeme & 2521 & 18.1 & 212 & 20.1 \\
Guaymas & 1336 & 9.6 & 218 & 6.0 \\
Navojoa & 1201 & 8.6 & 468 & 6.2 \\
Nogales & 1349 & 9.7 & & 13.3 \\
\hline
\end{tabular}

Fuente: Censo General de Población de Sonora, 1950, tomos I y II, Banco Nacional Hipotecario Urbano y de Obras Públicas, S.A., 1959.

Cuadro 2.

Población ocupada en el comercio de Sonora

por municipio, 1960

(porcentaje de participación)

\begin{tabular}{lccc}
\hline & $\begin{array}{c}\text { Población } \\
\text { ocupada total }\end{array}$ & $\begin{array}{c}\text { P. ocupada } \\
\text { en el comercio }\end{array}$ & $\%$ \\
\hline Sonora & 251005 & 26867 & 10.7 \\
Cajeme & 38480 & 5432 & 14.1 \\
Hermosillo & 37881 & 5641 & 15.0 \\
Navojoa & 17978 & 2210 & 12.2 \\
Guaymas & 17256 & 1982 & 11.4 \\
Nogales & 13265 & 2529 & 19.0 \\
\hline
\end{tabular}

Fuente: Elaboración propia con datos del VIII Censo General de Población, 1960, Secretaría de Industria y Comercio, Estado de Sonora, México, D.F., 1963. 
mismos se ocupaba $72 \%$ de los trabajadores comerciales. Al mismo tiempo, agrupaban a casi el 50\% del total de la población ocupada en el estado.

Una característica peculiar del comercio sonorense en este lapso fue su separación con las actividades productivas de la entidad, que eran la agricultura, la industria, la ganadería y la pesca. Otra particularidad fue que los establecimientos donde se ofrecían bienes de consumo personal, además de brindar en menores proporciones artículos elaborados en la entidad, dejaron de distribuir los insumos necesarios para las mencionadas actividades productivas. Ello condujo a la especialización de los establecimientos al comercializar productos para cada necesidad y por separado.

Otro factor a destacar en este periodo fue la ubicación de los supermercados en la localidad, por el alto grado de aceptación de los consumidores. Los supermercados ofrecían todos los productos que distribuía el gran abarrotero, pero en mayor diversidad y cantidad, con un precio fijo a la vista del consumidor y para ser escogido por él mismo. Además, cada artículo tenía impreso el nombre del producto y sus características. Es decir, se aplicaba la modalidad completa del autoservicio. La diferencia consistió en que este nuevo establecimiento comercial ofrecía la mercancía de manera directa y rápida por un lado, es decir, sin la atención del propietario o empleado del establecimiento, y por otro, el cobro del artículo se hacia a través de máquinas registradoras, ya con un precio permanente y previamente marcado en el producto. Todo ello agilizó aún más la adquisición de bienes, al mismo tiempo que se ofreció una mayor cantidad y diversidad de productos a un precio relativamente menor.

De esta forma, el comercio se distinguió como parte de las actividades económicas y se localizó conjuntamente a ellas. Simultáneamente, se concentró en las zonas de mayor crecimiento poblacional del estado, es decir, en los cinco municipios mencionados (cuadro 3). Después del auge minero, éstos han sido los ayuntamientos donde se han conjuntado las actividades económicas del estado hasta principios del siglo XXI.

Los municipios de Hermosillo, Cajeme, Guaymas, Navojoa y San Luis Río Colorado absorbían poco más del 55.5\% de la población ocu- 


\section{Cuadro 3}

Población ocupada en el comercio por municipio en Sonora, 1975

(porcentaje de participación)

\begin{tabular}{lrrcr}
\hline & $\begin{array}{c}\text { Población } \\
\text { ocupada }\end{array}$ & $\%$ & $\begin{array}{c}\text { P. ocupada } \\
\text { en el comercio }\end{array}$ & $\%$ \\
\hline Sonora & 284195 & 100.0 & 32838 & 11.5 \\
Hermosillo & 53552 & 18.8 & 7761 & 23.6 \\
Cajeme & 46983 & 16.5 & 7251 & 22.0 \\
Guaymas & 22703 & 8.0 & 2617 & 8.0 \\
Navojoa & 16705 & 6.0 & 2247 & 7.0 \\
S.L.R.C & 16422 & 6.0 & 2199 & 6.6 \\
\hline
\end{tabular}

Fuente: Censo General de Población y Vivienda, 1970, tomos I y II, INEGI.

pada del estado, simultáneamente al $67 \%$ del personal ocupado en el comercio de la entidad. La actividad comercial en Nogales decae en esta década, lo que da paso al crecimiento del comercio en San Luis Río Colorado. La tendencia en estos municipios registraba el mayor crecimiento demográfico, la generación de mayor población ocupada y el asentamiento de las actividades económicas más productivas del estado. Fueron también las localidades más representativas económicamente por los mismos factores desde 1950.

\section{La frontera virtual al interior del estado}

(Principios de los ochenta a la fecha)

En la actualidad el comercio de Sonora es influenciado por el mercado norteamericano, y no precisamente por su intercambio de productos a través de la frontera geográfica. Sin lugar a dudas esta relación comercial se sigue realizando, pero hoy como parte del proceso de transnacionalización de los mercados. El consumidor ya no tiene que trasladarse forzosamente a la frontera norte del país para la adquisición del producto estadounidense porque la frontera se ha trasladado al interior del estado, principalmente a la capital, Hermosillo, con la 
instalación de grandes centros comerciales que distribuyen los productos al mayoreo o al menudeo, como Price Club, Costco y Sam's Club, que corresponden a los primeros, y Wal Mart, Home Depot y Office Depot como ejemplo de los segundos. Aquí se ofrecen toda clase de artículos de importación procedentes de Estados Unidos, Taiwán, Vietnam, Hong Kong, Singapur y Corea, entre otras naciones. La gran diversidad de mercancías atrae al consumidor local que busca el mejor precio -el más bajo- aunque no siempre obtenga la mejor calidad en el producto.

La introducción de estos establecimientos a territorio sonorense marca una nueva etapa en la historia comercial de Sonora. Sus características son, en primera instancia, sus altos niveles de competencia en rubros como: presentación, precio, calidad, organización de la empresa, mercadotecnia, trayectoria en el mercado de su país y en el extranjero, redes de distribución, control de inventarios a través del código de barras e infraestructura en general. Este nuevo nivel de competencia rompe con la estructura comercial del estado conformada décadas atrás. En esta reestructuración que se gesta a raíz del nuevo orden competitivo, los comercios micros, pequeños y en menor medida los medianos y grandes sufren el desplazamiento del mercado. Los comerciantes líderes del grupo moderno dejaron de ser los empresarios oriundos de Sonora para dar paso a las empresas foráneas.

Ante los nuevos niveles de la competencia, los comerciantes locales de grandes dimensiones también son afectados, como es el caso del Grupo Corporativo Valenzuela Hermanos, que empieza a ser desplazado de su espacio comercial, el cual mantuvo casi a nivel de monopolio en las décadas de los setenta y ochenta. En ambas décadas cautivó más del $90 \%$ del mercado sonorense, mientras que hoy en día abarca poco menos del $23 \%$ de ese espacio comercial.

Otra empresa local, Mazón Hermanos, observó cada vez más reducido su margen de acción hasta desaparecer totalmente del mercado. A pesar de adquirir tecnología y modernizar su infraestructura, se enfrentó a un grave problema: no pudo reducir los precios al mismo ritmo que las empresas homólogas, por los altos costos con los que operaba.

Estos fenómenos registrados a partir de la apertura comercial de los ochenta y con el Tratado de Libre Comercio posteriormente obli- 
garon al comercio local a redefinir sus niveles de competencia. También se presenta el surgimiento de pequeños locales comerciales dedicados $100 \%$ a la venta de productos extranjeros, principalmente juguetes, decoración, regalos y arreglo personal.

Todos estos productos que se encuentran al interior del estado y la inversión directa del gran comercio van modificado poco a poco los patrones de consumo de la sociedad sonorense y las formas de obtener la preferencia del consumidor local.

Un ejemplo de los establecimientos comerciales trasnacionales que han recorrido las fronteras del consumo es la empresa Wal Mart. Las características generales de la empresa, con las cuales ejerce una competencia de alto nivel en la actividad comercial de la entidad, son las siguientes: por el valor de sus ventas es la empresa más grande del mundo, abastece a más de 30 mil tiendas independientes en Estados Unidos, cuenta con seis canales por satélite, con los cuales desarrolla un sistema de información gerencial en la disminución de costos y ahorro de tiempo en el control del mercado rural, por mencionar sólo algunas de sus características de operatividad.

En Sonora, Wal Mart genera alrededor de mil empleos directos. Esta inversión comprende dos establecimientos denominados Wal Mart Super Center, tienda surtida en alimentos, ropa y mercancía en general, y Club Aurrerá Sam's, orientado a la venta de mayoreo y medio mayoreo, con dos ubicaciones en Hermosillo y dos en Ciudad Obregón. ${ }^{8}$

${ }^{8}$ En 1997, la firma Wal Mart contabiliza entre todos sus establecimientos a 60 millones de clientes en una semana, 670 mil asociados, 2400 tiendas de descuento, 470 Sam's Club. Todos ellos ubicados en 50 estados de la Unión Americana y en países como Puerto Rico, México, Canadá, Brasil, Argentina, China e Indonesia. En México, Wal Mart se asoció a la empresa Cifra en 1991, de esta unión surge Sam's Club, que es el producto del convenio de inversión extranjera y transferencia de tecnología entre las cadenas comerciales más importantes y líderes de México y Estados Unidos: Cifra, S.A. de CV. y Wal Mart Stores, Inc., respectivamente. En el país se encuentran ya en operación 22 de estos establecimientos. Este club está dirigido a pequeños y medianos comerciantes, tiendas de abarrotes, farmacias, restaurantes, comedores industriales, establecimientos de servicios, oficinas y medio mayoristas ofreciendo más de 3500 artículos de uso frecuente a precios de mayoreo en el momento y la cantidad que los socios requieran. 
Son estas características con las cuales los establecimientos extranjeros se ubican en territorio sonorense influyendo en los hábitos de consumo, al mismo tiempo que imponen una modalidad competitiva que provoca el desplazamiento de los comercios en todas sus magnitudes, es decir, micros, pequeños, medianos e incluso grandes.

En Sonora, los años ochenta trajeron significativas modificaciones demográficas debido al cambio constante de la población rural a urbana en busca de mejores niveles de bienestar económico y social. Con ello se manifestaba la desequilibrada ubicación de la población respecto a los recursos disponibles, concentrándose tanto la población como las actividades productivas en los centros urbanos de Nogales, San Luis Río Colorado, Hermosillo, Ciudad Obregón y Navojoa, municipios donde también el comercio registró el mayor número de establecimientos. Es decir, el comercio se asentó alrededor de las localidades más productivas del estado y en constante crecimiento urbano y demográfico. Los establecimientos más numerosos estaban integrados principalmente por los giros de abarrotes, alimentos y bebidas, artículos de vestuario y uso personal, específicamente para responder a la demanda básica de la población. ${ }^{9}$

En la primera mitad de los ochenta, la concentración geográfica de los agentes comerciales es evidente. Así, $81 \%$ del total de establecimientos comerciales se localizaba en la zona costera del estado. Nuevamente, Hermosillo y Cajeme absorbieron el mayor porcentaje, el 46\% del total (Plan Estatal de Desarrollo 1986-1991).

Si la concentración demográfica, productiva y comercial se ubicaba principalmente en los municipios de Hermosillo y Cajeme, era lógico que la población ocupada en el comercio también se agrupara

\footnotetext{
${ }^{9}$ Hermosillo y Cajeme sobresalieron al concentrar entre ambos a la población ocupada y a la actividad comercial del estado en 1980. Estas localidades reunieron a casi el $40 \%$ de la población ocupada en el comercio; el capital comercial invertido en ellos fue del $71 \%$ y las ventas alcanzaron el $70 \%$ del total de la actividad, mientras que los comerciantes representaron, a su vez, el $48 \%$ de los establecimientos que integraban al grupo tradicional y al moderno en conjunto (Plan de Desarrollo Económico y Social 1980-1985). Es importante destacar que en estos municipios la actividad agrícola ha registrado una dinámica que ha permitido alcanzar cierto nivel de crecimiento económico al estado, aunado al auge industrial propiciado por las maquiladoras.
} 


\section{Cuadro 4}

Municipios representativos en número de establecimientos comerciales al menudeo en Sonora, 1985

\begin{tabular}{lrrrr}
\hline Localidades & Establecimientos & $\%$ & $\begin{array}{r}\text { Personal } \\
\text { ocupado }\end{array}$ & $\%$ \\
\hline Sonora & 10669 & 100.0 & 40309 & 100.0 \\
1. Hermosillo & 2593 & 24.3 & 11420 & 28.3 \\
2. Cajeme & 2355 & 22.0 & 8694 & 21.5 \\
3. Guaymas & 796 & 7.4 & 3219 & 7.9 \\
4. Navojoa & 794 & 7.4 & 3531 & 8.7 \\
5. Nogales & 660 & 6.0 & 2362 & 5.8 \\
6. S.L.R.C. & 619 & 5.8 & 2371 & 5.8 \\
7. Caborca & 386 & 3.6 & 1765 & 4.3 \\
8. Huatabampo & 315 & 2.9 & 1060 & 2.6 \\
9. Empalme & 289 & 2.7 & 736 & 1.8 \\
10. Puerto Peñasco & 269 & 2.5 & 815 & 2.0 \\
\hline
\end{tabular}

Fuente: Elaboración propia con datos del IX Censo Comercial, 1986, tomos I y II, INEGI.

mayoritariamente en los mismos municipios con el 50\% (cuadro 4). Entre estos ayuntamientos, incluyendo a los de Guaymas, Navojoa y Nogales, se agrupaba $76 \%$ de los establecimientos comerciales, mismos que daban ocupación al $72 \%$ de la población laboral del sector.

Entre las 10 primeras localidades se concentró el $85.4 \%$ de las unidades comerciales, dejando el resto, $14.6 \%$, a los 60 municipios que integraban el estado en 1985. De igual manera, $89 \%$ de los trabajadores comerciales se agruparon en estos 10 municipios.

En los primeros cinco municipios, específicamente en sus cabeceras, se situaron los agentes comerciales más representativos del grupo moderno. Entre éstos se localizaban las tiendas de supermercados que continuaron siendo las más numerosas dentro de este grupo, seguidas de las departamentales y almacenes.

Las primeras (tiendas de supermercados) poseen una integración vertical de la actividad comercializadora, es decir, cuentan con su propia red de transporte, almacenamiento y conservación. Como consecuencia, realizan operaciones en escalas mayores, tanto a la compra 
como a la venta, obteniendo elevados márgenes de ganancias al ofrecer una diversidad de productos con un margen de comercialización bajo. Todo ello permitido por el desempeño de una estructura de costos favorable.

Mención especial merece el municipio de San Luis Río Colorado, que exhibió una nueva posición al pasar del sexto lugar, en 1985, al tercer nivel en 1993 (cuadro 5). Este municipio fronterizo elevó su crecimiento económico, poblacional y de infraestructura urbana impulsado por la expansión de la industria maquiladora de exportación, aunado al desarrollo agrícola que ha imperado en la región. El empleo generado por la industria ensambladora permitió la expansión de algunas unidades comerciales. Ejemplos recientes de éstas son Waldos y Sólo un Precio como tiendas de autoservicio.

Como puede observarse, Sonora no pierde su tendencia de crecimiento y cambios en la estructura del comercio localizado en las ciudades contiguas a los valles del estado. Situación contraria registró la zona serrana en el mismo periodo, donde en 40 municipios sólo se

\section{Cuadro 5}

Municipios representativos por el número de establecimientos comerciales en Sonora, 1993

\begin{tabular}{lrrrr}
\hline & Establecimientos & \multicolumn{1}{c}{$\%$} & $\begin{array}{r}\text { Personal } \\
\text { ocupado }\end{array}$ & $\%$ \\
\hline Sonora & 24794 & 100.0 & 82327 & 100.0 \\
1. Hermosillo & 6820 & 27.5 & 27778 & 34.0 \\
2. Cajeme & 4801 & 19.3 & 17807 & 22.0 \\
3. S.L.R.C. & 1675 & 7.0 & 4927 & 6.0 \\
4. Guaymas & 1589 & 6.4 & 5051 & 6.0 \\
5. Navojoa & 1585 & 6.3 & 5448 & 7.0 \\
6. Nogales & 1361 & 5.0 & 4751 & 6.0 \\
7. Caborca & 816 & 3.2 & 2703 & 3.0 \\
8. Etchojoa & 796 & 3.2 & 1517 & 2.0 \\
9. Huatabampo & 781 & 3.1 & 2214 & 3.0 \\
10. Agua Prieta & 681 & 3.0 & 1668 & 2.0 \\
\hline
\end{tabular}

Fuente: Gobierno del Estado de Sonora, INEGI, Anuario Estadístico del Estado de Sonora, 1996; IV Informe de Gobierno de Manlio F. Beltrones Rivera, 1995. 
ubicaba el 5\% de los establecimientos comerciales, es decir, 603. Evidentemente, esto se relaciona con la existencia de un mercado serrano muy pequeño, ya que en estos municipios sólo habita $10 \%$ de la población estatal.

En 2005, los municipios de Hermosillo y Cajeme continúan siendo los más dinámicos en la economía estatal. La capital del estado conserva su posición dominante en el total de unidades productivas, sin embargo, Cajeme posee menos unidades industriales que Nogales (cuadro 6). En el número de establecimientos comerciales se sigue dando la tendencia de crecimiento principalmente en Hermosillo y Cajeme, localidades donde se concentran los empresarios líderes de esta actividad, tanto nacionales como extranjeros, y por consecuencia donde primero se registran los cambios que impone este grupo minoritario.

\section{Conclusiones}

Aun cuando en el ámbito de la ciencia económica el énfasis suele ponerse en el análisis de las actividades productivas, el comercio desempeña una función clave en la economía por varias razones: permite formar mercados que van desde lo local hasta lo global y es el principal vehículo de realización dineraria de todo tipo de mercancías. En este sentido vale destacar que desde el siglo XIX, Alfred Marshall ana-

\section{Cuadro 6}

Establecimientos productivos en Sonora, 2005

\begin{tabular}{lrrrrcrc}
\hline Municipio & Total & Industria & $\%$ & Comercio & $\%$ & Servicios & $\%$ \\
\hline Hermosillo & 3737 & 145 & 3.88 & 2687 & $71.90 \%$ & 905 & 24.22 \\
Cajeme & 1970 & 40 & 2.03 & 1625 & $82.49 \%$ & 305 & 15.48 \\
Magdalena & 418 & 3 & 0.72 & 293 & $70.10 \%$ & 122 & 29.19 \\
Nogales & 300 & 57 & 19.00 & 157 & $52.33 \%$ & 86 & 28.67 \\
Cananea & 298 & 2 & 0.67 & 239 & $80.20 \%$ & 57 & 19.13 \\
Guaymas & 276 & 20 & 7.25 & 182 & $65.94 \%$ & 74 & 26.81 \\
Navojoa & 191 & 30 & 15.71 & 126 & $65.97 \%$ & 35 & 18.32 \\
\hline
\end{tabular}

Fuente: Estimaciones propias con datos del SIEM, 2005. 
lizó el comercio en la perspectiva de su relevancia en el conjunto del sistema económico de mercado. Y no obstante que con el transcurso del tiempo tanto la producción como el consumo presentan características más complejas, la reproducción humana exige una base de oferta de mercancías denominadas de consumo personal que está en función del tamaño de los mercados y de los ingresos de la población. Esto explica el perfil que el comercio ha tenido en Sonora en cada una de los periodos reseñados en este trabajo.

En cada uno de los cuatro episodios de la historia comercial de Sonora se manifiesta, por un lado, como efecto inmediato, el reacomodo de las élites empresariales de los comercios tanto locales como regionales, con la finalidad de seguir manteniendo su posición en la actividad; y por el otro, se advierte la influencia que ejerce la oferta diversa de los bienes en los hábitos de consumo del pueblo sonorense.

Después de haber realizado un recorrido por la historia económica del comercio en Sonora, se advierte que la etapa actual iniciada en la década de los ochenta del siglo pasado tiene rasgos cualitativamente muy diferentes respecto a las tres anteriores, ya que se presenta en un contexto de integración comercial cada vez mayor entre los países, que tiene como agente principal las grandes cadenas comerciales trasnacionales que unen países, regiones y localidades. Estos movimientos obedecen a la búsqueda de mayores espacios en el mercado a nivel internacional, que necesita cubrirse con grandes volúmenes de mercancías que puedan mantenerse a precios bajos.

La modificación en la estructura comercial empieza por los grandes empresarios comerciales de la localidad y de la región, los cuales controlan y definen el consumo en la sociedad sonorense. Al introducirse los establecimientos comerciales extranjeros se inicia una nueva fase de competencia por el ingreso del consumidor local mediante un esquema que controla el comercio y marca las pautas de consumo para la sociedad, aunque no necesariamente responde a la satisfacción de necesidades comunes y apremiantes.

La oferta de productos importados tiende a desplazar a los distribuidores locales, regionales o nacionales, modificando y adecuando sus formas de consumo de acuerdo a la oferta. Ése es el caso del cierre de tiendas que se dedicaban a la venta de productos nacionales como 
Mexsuiza, Novedades Duarte, Zaragoza, entre otras. En su defecto, para poder permanecer en el mercado tienen que adquirir productos importados, como sucedió con Valenzuela Hermanos y Mazón Hermanos, que finalmente sucumbió ante la nueva competencia.

En este entorno resurgen los "tianguis" que ofrecen mercancía importada y se da la apertura de pequeños establecimientos comerciales dedicados en su totalidad a la venta de productos extranjeros, principalmente juguetes, artículos para el arreglo personal y de decoración.

Las formas de consumo tradicional tienden a modificarse de manera acelerada en los centros urbanos a través del consumo de importación y por la influencia de los medios de comunicación. La influencia de los Estados Unidos en Sonora data desde finales del siglo XIX y hoy en día continúa con más ímpetu que nunca.

En síntesis, la nueva competencia ejercida por las empresas extranjeras en el estado se expresa en lo siguiente: a) bajos costos de operación, que se obtienen básicamente por el alto grado de tecnología utilizado en el transporte de productos, control de la venta de mercancías y de proveedores, bajo el esquema del código de barras y el scanner; $b$ ) infraestructura para la operación del comercio, la dimensión de los locales es de los hipermercados o megamercados, con grandes espacios para estacionamiento, oficinas y otros comercios complementarios más pequeños como panadería, farmacia, fotografía, restaurantes, bancos, etcétera. Dentro de este rubro encontramos también grandes pasillos con anaqueles y refrigeradores de elevadas dimensiones ofreciendo toda clase de productos; $c$ ) calidad en el producto, es decir, materiales más resistentes, durables y de mejores características en general, además de la extensa diversidad y cantidad de productos en venta; $d$ ) capacitación al personal, que prioriza la atención "amable" al cliente; e) precio bajo, pues los reducidos costos de operación inducen a una disminución en el precio de venta del producto, muy por debajo de la competencia local; f) la ubicación de los establecimientos comerciales en todas sus dimensiones (micros, pequeños, medianos y grandes) se instalan principalmente en los municipios económicamente más productivos y de mayor crecimiento demográfico. 
Éstos son, entre otros, los factores que definen la etapa actual de comercialización interna de bienes de consumo personal en la entidad, enmarcada en el contexto del proceso de globalización de los mercados.

\section{Bibliografía}

Bocanegra Gastelum, Carmen, 1997, “Competencia e integración internacional del comercio en Sonora", en México y Estados Unidos, el reto de la interdependencia económica, Blanca Lara y Lorenia Velázquez (comps.), Colegio de Economistas de Sonora, A.C. y otros, Hermosillo, Sonora.

Bocanegra Gastelum, Carmen y Miguel Ángel Vázquez Ruiz, 2004, "El comercio minorista en el norte de México: agentes de Sonora y Chihuahua", Estudios Sociales, vol. XX, núm. 23, CIAD, A.C., Hermosillo, Sonora, enero-junio de 2004. 2003, El comercio interno en Sonora y su encuentro con la globalización, 1980-2000, tesis de doctorado, Universidad Autónoma de Sinaloa, Culiacán.

Censo General de Población de Sonora, 1950, tomos I y II, INEGI.

Castillo Berthier, Héctor, 1994, Estructura de poder de los comerciantes mayoristas de abarrotes de la Ciudad de México, Cuadernos de Investigación, Universidad Nacional Autónoma de México-Instituto de Investigaciones Sociales, México.

Espinoza, José A., 1932, El ejemplo de Sonora, México.

Gobierno del Estado de Sonora-Dirección de Planeación y Fomento Industrial, 1967, Sonora. Desarrollo industrial, 1961-1967, Hermosillo, Sonora. ,1980, Plan de Desarrollo Económico y Social, 1980-1985, Hermosillo, Sonora.

1986, Plan Estatal de Desarrollo, 1986-1991, Hermosillo, Sonora. 1996, Anuario Estadístico del Estado de Sonora, INEGI. 1995, IV Informe de Gobierno de Manlio F. Beltrones Rivera.

Gutiérrez, Daniel Carlos, 1993, “Las formas y orientaciones del consumo en la sociedad de la frontera sonorense", en Juan Manuel Sandoval Palacios (comp.), Las fronteras nacionales en el umbral de 
dos siglos, Seminario Permanente de Estudios Chicanos y de Fronteras, INAH, México.

INEGI, 1970, Censo General de Población y Vivienda, tomos I y II. 1986, IX Censo Comercial, tomos I y II.

Jeannot Rossi, Fernando, La economía de mercado en el siglo XXI. Fundamentos institucionales, Diana, México.

Marshall, Alfred, 1954, Principios de economía, Ediciones Aguilar, Madrid.

Marshall, Alfred, 1978, Obras escogidas, Fondo de Cultura Económica, México.

Martínez de Castro, María B., 1995, Hermosillo de mis recuerdos, Casa de la Cultura de Hermosillo-Instituto de Cultura Superior de Sonora, A.C., Hermosillo, Sonora.

Marx, Carlos, 1982, El capital. Crítica de economía política, tomo III, Fondo de Cultura Económica, México.

Secretaría de Industria y Comercio, 1963, VIII Censo General de Población, 1960, México.

Smith, Adam, 1985, Investigación sobre la naturaleza y causas de la rique$z a$ de las naciones, Fondo de Cultura Económica, México.

Tinker, Salas Miguel, 1994, "Del crédito al contado. Cambios en el comercio de Sonora después de 1850", en revista El Colegio de Sonora, año V, núm. 8, Hermosillo, Sonora. 